\title{
Self-Identity of Adolescents in the Cross-Cultural Aspect (on the example of Mongolian and Russian Adolescents)
}

\author{
Tuyana Ts. Dugarova ${ }^{1 *}$, Evgeniya M. Trofimova ${ }^{2}$, Aldar V. Damdinov ${ }^{3}$, Larisa A. Andreeva ${ }^{4}$, \\ Lidiya P. Sagalakova ${ }^{5}$, Irina Zh. Shakhmalova ${ }^{6}$, Tumen-Zhargal Ts. Dugarov ${ }^{7}$ \\ ${ }^{1}$ Department of Developmental Personality Psychology, Moscow Pedagogical State University, Moscow, Russia \\ ${ }^{2}$ Department of General Psychology and Labor Psychology, Russian New University, Moscow, Russia \\ ${ }^{3}$ Department of General and National History, Buryat State University, Ulan-Ude, Russia \\ ${ }^{4}$ Department of Pedagogy and Psychology, East Siberian State Institute of Culture, Ulan-Ude, Russia \\ ${ }_{5}^{5}$ Department of Department Subject-Cycle Commission of Pedagogy and Psychology, Tuvan State University, Kyzyl, Russia \\ ${ }^{6}$ Department of Pedagogy and Methods of Primary Education, Nerungri Technical Institute (branch) of M.K. Ammosov North-Eastern Federal \\ University, Nerungri, Russia \\ ${ }^{7}$ Faculty of Informatics and Control Systems, Moscow Polytechnic University, Moscow, Russia
}

Received: 18/12/2019 Accepted: 19/03/2020_ Published: 20/02/2020

\begin{abstract}
The article represents the empirical research results on self-identification of Mongolian and Russian adolescents. The research hypothesis is the assumption that there are culturally determined differences in the structure and content of the components of Mongolian and Russian adolescents' personal and social identities. The sample of subjects consists of 185 adolescents aged 12 to 15 years (94 adolescents living in the city of Khovd (Western Mongolia) and 91 adolescents living in Biysk (Altai Region). The main research method is a non-standardized test of M. Kuhn, T. McPartland "The Twenty Statements Test". Statistically significant differences in the content components of identity are obtained, which are determined by the respondents' nationality and gender. On the basis of the hierarchical cluster analysis, the self-description content and structural differences in the adolescents of different nationalities are distinguished.
\end{abstract}

Keywords: Identity, self-identification, social and personal identity, traditional values, adolescents, cross-cultural aspect

\section{Introduction}

The transitivity of modern society and its changing values in the context of the "ethnic and cultural clash" exacerbate the problem of identity as a global problem of our time and stimulate the search for mechanisms contributing to the world and life perception in the diversity of cultures and human relations. From the standpoint of post-non-classical methodology, the phenomenon of identity being a complex self-developing system is presented as an interdisciplinary object. This gives rise to a multiplicity of approaches and a polysemantic nature of the term itself. So, in psychology the concepts of self-awareness, self-identification and self-concept are distinguished. The comparison of these concepts shows their partial inclusion in each other (more about this: [1]).

The first most complete definition of identity is given by $\mathrm{E}$. Erikson (1996), who describes it as an internal continuity and self-identity of a person, emotional integration, selfidentification with certain social roles [2]. Other definitions of identity are so varied that it makes sense to focus on the most general one: it is "the experience of self-identity" [3], the experience of the personal self.

The desire to make the description of identity more formalized and specific led to the allocation of two types (components) of identity - personal and social. Both components are not autonomous from each other. First, they are included in a shared dynamic continuum, expressed in $\mathbf{J}$. Turner's theory of self-categorization: “... social identity extends to the personal self, ... social norms determine and shape the activity of the personal self and vice versa" [4]. The relation of personal and social identities is not constant and depends on the life circumstances in which the person finds himself at the moment. Secondly, personal identity cannot be isolated from social one, since personal characteristics are also assessed based on comparing oneself with others, through the evaluation of others [5]. It is society that establishes those characteristics and the degree of their manifestation by which a person is evaluated. Thus, individual personal characteristics become social values indicators of a particular society.

In the era of globalization, the research mainstream is a cross-cultural approach that considers the sociocultural conditioning of the phenomenon of identity. Within culturalhistorical psychology the studies of identity transformations, cultural and social identity formation are presented. The works analysis, devoted to the genesis of identity, demonstrates the importance of the correspondence between the constructed internal identity and the socio-cultural environment. Research strategies, as a rule, are aimed at identifying components of identity (cognitive, affective), much less often the relation between social and personal identification is studied within the cross-cultural approach. The influence of historical and cultural features of society, the interconnection between identity and psychological, socio-cultural variables, certain types of identity in different cultural and ethnocultural groups require special attention of researchers.

Corresponding author: Tuyana Ts. Dugarova, Department of Department of Developmental Personality Psychology Moscow Pedagogical State University, Moscow, Russia. E-mail: dugarovatts@gmail.com 
Psychologists explain the high scientific interest in the identity of adolescents in the cross-cultural aspect by the need to identify socialization patterns in a multicultural society and to study culturally determined differences in components of personal and social identities.

Teenagers belonging to a traditional society find themselves in special "conditions of conjugation between the world of tribal traditions and the world of cultural integration" (Mongolian people belong to a little modernized traditional culture, preserving social organization structure, traditional forms of socialization and upbringing, ethnic customs and traditions). The relevance of our research consists in the acute demand for knowledge about the identity of adolescents, who are characterized by a special sensitivity to changes in society, especially to intra-ethnic and interethnic processes. The identity formation of adolescents is associated with the interaction with "theirs" and "others", with "their" traditional values and values of the "other" globalization world [6, 7].

\section{Materials and Methods}

The research goal was to study self-identification characteristics of modern Mongolian and Russian adolescents in the cross-cultural aspect. The hypothesis of the research was the assumption that there are culturally determined differences in the structure and content of personal and social identities components of Mongolian and Russian adolescents. The sample of subjects consisted of 184 adolescents aged 12-15 years (94 Mongolian adolescents (Hereinafter, the words "Mongolian" and "Russian" will denote teenagers of Mongolia and Russia as carriers of the corresponding cultures), 47 boys and 47 girls living in the city of Khovd (Western Mongolia) and 90 Russian adolescents, 45 boys and 45 girls, living in Biysk (Altai Region).

The methodology of "The Twenty Statements Test" (modified by T.V. Rumyantseva [8]) was used as a diagnostic tool. The modification allows us to explore a subject's selfesteem, and also offers a scheme for a formal-meaningful analysis of the test results according to the following indicators: gender identity, self-esteem, level of reflection, temporal identity, level of identity differentiation, relation between social roles and individual characteristics, reflection of the main life spheres and predominance of various identity components.

To obtain data on self-esteem, T.V. Rumyantseva [8] made the following modifications to the diagnostic procedure and the results analysis: after writing his characteristics, a subject must evaluate each of them by a four-digit system (as positive, negative, ambivalent or with an unformed assessment). The relation between positively assessed qualities and negative ones allows the researcher to define types of self-esteem (adequate, inadequately overestimated and underestimated, unstable) based on the norms given by T.V. Rumyantseva [8].

The results were processed by using the content analysis (in the program "Content Analysis 1.6"). Further data processing was carried out by using the IBM SPSS Statistic 22 software. The comparison of the responses distribution by categories in different samples was carried out by using Pearson's $\chi 2$ test. To analyze the self-descriptions structure, the hierarchical cluster analysis by Ward's method for standardized values was used.

\section{Results and Discussion}

The research results of Mongolian and Russian adolescents were considered as follows: self-descriptions analysis, selfassessment analysis, comparative analysis of self-descriptions in order to identify differences in the identity structure of Mongolian and Russian adolescents. The structural and content analysis of self-descriptions was carried out by using the content analysis, where seven groups of adolescents' selfdescriptions were identified. The content analysis results are presented in the Table 1 . The selected self-descriptions groups for the general adolescents sample include: features relating to macrogroups; personal characteristics; gender characteristics; features related to the social role of a teenager in the family; communication characteristics; active identity features; appearance characteristics.

Table 1: Frequency of identity indicators occurrence in self-descriptions of Mongolian and Russian adolescents

\begin{tabular}{|c|c|c|c|c|c|c|c|}
\hline \multirow[b]{2}{*}{$\begin{array}{l}\text { Components and } \\
\text { indicators of } \\
\text { identity }\end{array}$} & \multicolumn{6}{|c|}{ Frequency of occurrence (\%) } & \multirow[b]{2}{*}{$\begin{array}{l}\text { Significance } \\
\text { (by criterion } \\
\left.\chi^{2}\right)\end{array}$} \\
\hline & $\begin{array}{l}\text { Boys - } \\
\text { Mongolian }\end{array}$ & $\begin{array}{l}\text { Girls - } \\
\text { Mongolian }\end{array}$ & $\begin{array}{l}\text { Boys - } \\
\text { Russian }\end{array}$ & $\begin{array}{l}\text { Girls - } \\
\text { Russian }\end{array}$ & $\begin{array}{l}\text { Total for } \\
\text { the } \\
\text { Mongolian } \\
\text { sample }\end{array}$ & $\begin{array}{l}\text { Total for } \\
\text { the } \\
\text { Russian } \\
\text { sample }\end{array}$ & \\
\hline Reflexive identity & 91,5 & 89,4 & 95,6 & 100 & 90,4 & 97,8 & 0,035 \\
\hline $\begin{array}{l}\text { Overall identity } \\
\text { assessment }\end{array}$ & 14,9 & 42,6 & 24,4 & 15,6 & 28,7 & 20,0 & 0,169 \\
\hline Active identity & 95,7 & 74,5 & 91,1 & 82,2 & 85,1 & 86,7 & 0,761 \\
\hline Human & 23,4 & 19,1 & 46,7 & 24,4 & 21,3 & 35,6 & 0,032 \\
\hline Name & 19,1 & 27,7 & 4,4 & 2,2 & 23,4 & 3,3 & 0,000 \\
\hline Physical identity & 57,4 & 36,2 & 42,2 & 51,1 & 46,8 & 46,7 & 0,985 \\
\hline Age & 25,5 & 31,9 & 4,4 & 6,7 & 28,7 & 5,6 & 0,000 \\
\hline Perspective identity & 36,2 & 51,1 & 8,9 & 17,8 & 43,6 & 13,3 & 0,000 \\
\hline Family identity & 66,0 & 91,5 & 31,1 & 46,7 & 78,7 & 38,9 & 0,000 \\
\hline Civic identity & 10,6 & 27,7 & 11,1 & 8,9 & 19,1 & 10,0 & 0,080 \\
\hline Ethnic identity & 27,7 & 23,4 & 2,2 & 6,7 & 25,5 & 4,4 & 0,000 \\
\hline Child & 25,5 & 23,4 & 2,2 & 0 & 24,5 & 1,1 & 0,000 \\
\hline Urban identity & 14,9 & 36,2 & 2,2 & 2,2 & 25,5 & 2,2 & 0,000 \\
\hline Student identity & 91,5 & 93,6 & 60,0 & 64,4 & 92,6 & 62,2 & 0,000 \\
\hline Religious identity & 0 & 2,1 & 4,4 & 4,4 & 1,1 & 4,4 & 0,159 \\
\hline Gender identity & 38,3 & 44,7 & 31,1 & 26,7 & 41,5 & 28,9 & 0,074 \\
\hline Friendly identity & 42,6 & 59,6 & 24,4 & 28,9 & 51,1 & 26,7 & 0,010 \\
\hline
\end{tabular}

Note: the last column shows the overall statistical significance of the differences between the Mongolian and Russian samples according to Pearson's $\chi 2$ test. 
In order to analyze statistically significant differences between the data obtained in the Mongolian and Russian samples, the Pearson chi-square was calculated, for which the data were converted to a dichotomous scale (the presence of the feature (s) was indicated by one, and its (their) absence - by zero). The comparison of the self-descriptions results in pairs by nationality and gender showed a much greater number of differences between Mongolian and Russian adolescents than between boys and girls.

The comparative analysis of Mongolian and Russian adolescents' self-descriptions results revealed the following differences at a high significance level of 0.000. Mongolian adolescents distinguish features associated with name and age, with time perspective, with family and ethnic identity, and with social roles (student, family member). The comparison of the Mongolian and Russian samples results revealed significant differences $(p<0.05)$ in the frequency of identifying reflexive identity features, as well as defining oneself through a person's status. There were no statistically significant differences in

describing their external features, defining oneself through a general assessment, religious affiliation, and as a subject of activity. The comparative analysis of boys' and girls' selfdescriptions of both nationalities showed that the differences in the descriptions of Mongolian boys and girls relate to the general assessment of personality, activity features, family identity ( $\mathrm{p}<0.01$ ); appearance features, civic and urban self ( $\mathrm{p}$ $<0.05$ ). It is natural that Mongolian boys often mention appearance features (the most frequent of which are height and physical strength) and motor skills and abilities. There are no statistically significant differences in the self-descriptions of Russian boys and girls, with the exception of the feature "person", which was much more frequently mentioned by boys ( $p$ <0.05). The analysis of adolescents' self-esteem indicators showed the prevalence of adequate self-esteem $(41 \%)$. The importance of emotional-evaluative self-assessment in Mongolian adolescents was revealed. The results of the hierarchical cluster analysis by Ward's method for standardized values are presented in Figures 1,2. The clustering results shown in Figure 1 allow us to distinguish four clusters. The first of them is opposed to all the others and determines active identity and external parameters associated with it. The other three clusters are connected with each other at a low similarity level. The second cluster has to do with personal identity features: character traits, religious affiliation, plans for the future and general assessment of oneself. The third cluster describes social identity and combines features associated with the interaction in small groups (a family, a class). The fourth cluster is also connected with social identity, but combines features associated with the awareness of oneself as a member of a large conventional group (ethnos, humanity, etc.).
Human

Child

Gender identity

Ethnic identity

Name

Civic identity

Urban identity

Friendly identity

$>$ Age

Student identity

Family identity

Reflexive identity

Religious identity

Overall identity assessment

Perspective identity

Active identity

Physical identity

\section{Dendrogram using Ward's method} Aligning a cluster of rescaled distances

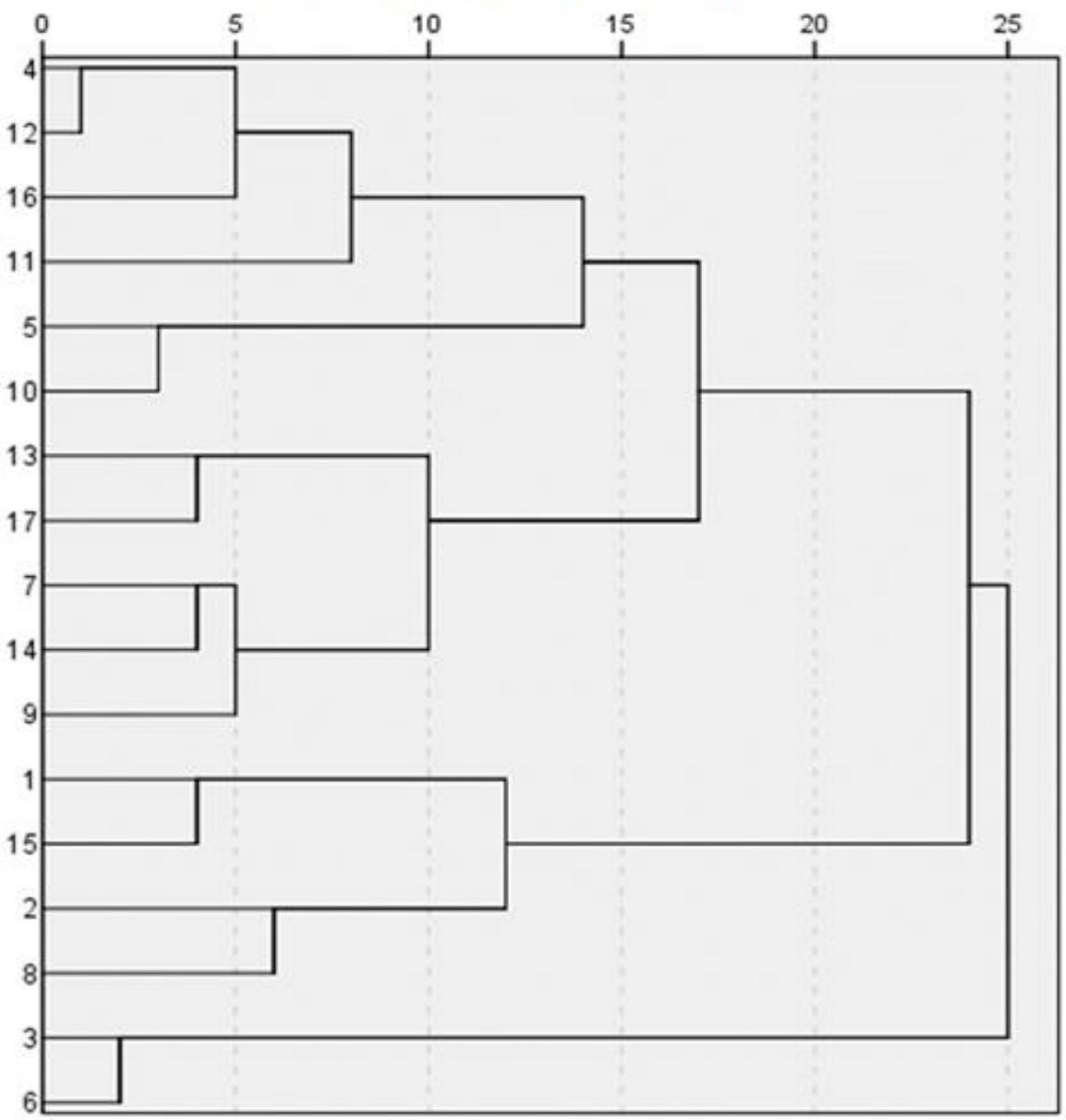

Figure 1: The result of clustering the self-descriptions data of Mongolian adolescents 


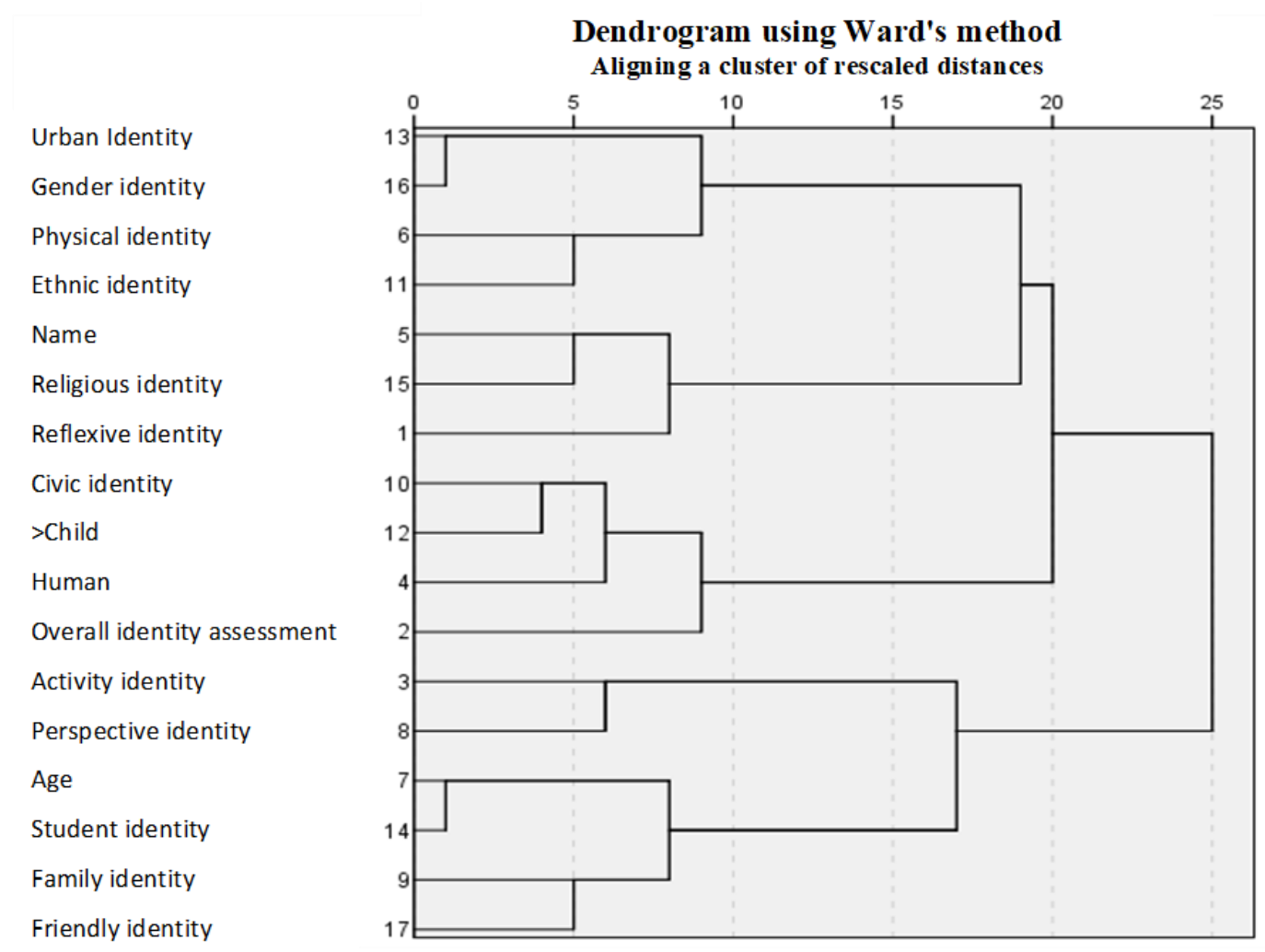

Figure 2: The result of clustering the self-descriptions data of Russian adolescents

The analysis of the self-descriptions clustering results of Russian adolescents allows us to distinguish five clusters. The two big clusters share active identity and associated features, which are related to a teenager interaction with the immediate environment, and reflexive identity with features that do not depend on a person (gender, nationality, etc.). Reflexive identity with adjoining religious identity and name (the last two features were rarely mentioned by Russian subjects) was clearly distinguished into a separate cluster. The rest of personal identity features are combined into one cluster with social identity features.

In this section, we will summarize the results obtained above, which are of the greatest significance, discuss the results from the point of view of the research hypothesis, and show how our results agree with the results of other researchers.

Let's consider self-descriptions features by the seven groups identified. The first self-descriptions group is represented by the largest number of responses and includes features that classify a teenager in macrogroups. The number of these features in the Mongolian adolescents' descriptions is significantly higher for all identity components: civic $(\mathrm{p}=$ $0.080)$, ethnic $(\mathrm{p}=0.000)$, urban $(\mathrm{p}=0.000)$, and student $(\mathrm{p}=$ 0.000 ). The Mongolian respondents describe themselves as a Mongolian, a citizen of Mongolia, a resident of a certain settlement and a student of a certain school. While the Russian adolescents do not specify their locality and school, but often mention the roles associated with conditional interest groups: a gamer, a sportsman, a music lover.

The second group of content characteristics includes personal characteristics. The analysis of personality traits attributed to themselves by the Russian adolescents shows their greater structure in comparison with the Mongolian selfdescriptions. In addition, the number of reflexive identity features in the Russian self-descriptions is significantly greater than that of the Mongols $(p=0.035)$. The content analysis of the Mongolian respondents' features presents them as socially approved, aimed at helping their neighbor - hardworking, helping; other qualities are manifested in communication with peers and reflect the image of a friendly teenager. In the Russian self-descriptions, many features are represented by antonymous pairs (especially in the girls' ones). Moreover, the hardworking / lazy dichotomy more frequently refers to the lazy one, which is practically absent in the Mongolian descriptions. Even if a Mongolian teenager describes himself / herself as "lazy" he / she phrases it this way: "hardworking, but sometimes lazy".

In the self-descriptions, gender characteristics are mentioned by $41.5 \%$ of the Mongolian respondents and $28.9 \%$ of the Russians $(\mathrm{p}=0.074)$ indirectly through the family role indication (a daughter, a son, a sister, etc.) or through the direct gender naming (a girl, a boy, a man, a woman). The Russian boys' responses reflect their stereotyping under the mass media influence: a man, a Lovelace, a macho, a lady's man, which is not typical for the Mongolian boys, whose characteristics are mostly formal and emotionally neutral. The girls' characteristics of both nationalities are more formal (a girl, a lady). The overwhelming majority of the boys' responses were emotionally neutral; they rarely ascribe to themselves emotionally negative features; isolated responses were emotionally positive (a handsome guy). In the Mongolian girls' self-descriptions, half of the responses were emotionally negative (an ordinary, simple girl). As for the Russian girls, such responses make up a quarter. At the same time, the adolescents who indicated gender characteristics in the features list always put them in the first ten positions. This shows the importance of these characteristics in their self-identification.

The fourth group consists of features associated with the social role of a teenager in the family. In the Russian descriptions, family roles are mentioned almost twice less often than those of the Mongols $(p=0.000)$. Moreover, they are represented only by a family role statement (a son, a brother, a daughter, a sister, a granddaughter) without specifying and 
giving it additional emotional coloring. In the Mongolian descriptions, such a role is almost always concretized by indicating a child's birth order in the family (an eldest son / daughter) or referring to another family member (a son / daughter of the father (almost never - of the mother)). Apart from the direct family role naming, the descriptions often contain indirect indications of family ties through the references to their household duties: cleaning the house, taking the younger children from kindergarten, cooking dinner, etc. In the Russian self-descriptions, there is practically no indirect mention of family ties.

The fifth self-description group combines characteristics related to communication. The only characteristic frequently mentioned by the Mongolian adolescents (I have many friends) is of a stating nature and not significant in the life of a teenager. When pointing out relations with society, the adolescents wrote such features as: I love parents, classmates, teachers, and never - I love friends. in In the Russian adolescents' self-descriptions the mention of their friendly roles is even less common and also has a stating character: a friend, a girlfriend.

The last two groups combine characteristics, the use frequency differences of which in the Mongolian and Russian samples are statistically insignificant. The sixth group was represented by active identity features, which is reflected in the Russian descriptions with the same frequency as in the Mongolian ones. At the same time, the self-description content is different: the Mongolian adolescents describe themselves through their physical skills, domestic work duties, and the Russian ones - through their favorite activities, the main of which are: walking, listening to music, drawing, reading, playing on the computer, singing.

The seventh group consists of appearance characteristics, the total number of which in the adolescents' self-descriptions in both samples is small. The only frequency characteristic in this series among the Russians is a general appearance assessment (handsome / ugly, on average, 13\% of subjects), among the Mongols - tall / short (5\% of boys).

So, self-descriptions of the Mongolian respondents show the predominance of We-images (civic, ethnic, regional, school self-identifications), pro-social orientation, gender selfidentification, the importance of family-role relations, reflection of friendship and comradeship values, sports and labor activity, the identification of sports-related physical features. The content analysis of the Russian adolescents' characteristics shows their greater involvement in reference interest groups, personality traits differentiation, predominance of reflexive identity, stereotyped gender role, insufficient reflection of the family sphere, focus on hobbies and appearance. The comparison of the self-description results by nationality and gender showed a greater significance of the first factor compared to the second one.

The self-description analysis makes it possible to state the prevalence of social identification over personal one in the selfidentification of a Mongolian adolescent, regardless of gender. Social identity characteristics in the Mongolian selfdescriptions make up 35\% of the total (in the Russian ones only $15 \%$ ). However, the personal identity characteristics of the Mongolian adolescents have a clear social orientation, they are consistent with the code of behavior in the traditional Mongolian culture, and are closely associated with the current traditional values "duty to the clan, tribe, nation", "duties of a family and society member" $[9,10]$. The Mongolian adolescents are much more likely to use their name as a defining feature. Traditionally, the name performs several functions (from protective to symbolic), it reflects generations succession and a family genealogy. Until now, in traditional societies, it is considered worthy to remember names of ancestors, which promotes clan consolidation and deep tribal ties of the Mongolian people $[6,7,11]$.

Age is a significant feature (rights, duties and status of a traditional society member are determined by age). In the selfdescriptions of a Mongolian adolescent claiming status in society, there are clearly visible value orientations towards traditions and customs - the code of laws of their ancestors. Thus, the family concept reflects nationally-specific ideas about family traditions, norms of intrafamily communication between parents and children, older and younger people, men and women. The pronounced sports and labor activity of adolescents is conditioned by physical and labor education traditions in Mongolia from early childhood (horse riding, national wrestling, archery). Our results are consistent with the results of other researchers, which show a much greater influence of social (including family) norms on leisure and preferred types of activity [12]. For Mongolian girls, it is more important than for boys to realize their belonging to a family, city, country, that is, to various social groups. It is curious that the studies in which American citizens of both sexes acted as subjects gave similar results [13]. This allows us to consider this trend as generally independent of cross-cultural differences.

A modern Mongolian teenager feels like a part of a single whole, in connection with which there are frequent definitions of himself as a Mongol, a citizen, a member of a family, headed by the father, and in which everyone has a range of responsibilities. The self-descriptions of adolescents convey the idea of part and whole connectedness, the integrity of the traditional Mongolian worldview. Earlier identity studies of Western and Eastern cultures representatives also show the predominance of an independent and interdependent view of their "Self", respectively $[13 ; 14]$.

Our data also correspond with the results obtained in the research of Mongolian students' traditional values. The research results have shown an orientation towards collectivism and mutual help among Mongolian students in comparison with Russian ones [11]. This is due not only to cultural traditions, but also to the people number. According to the sociopsychological research data, people belonging to smaller groups think more about their group membership in comparison with large groups members [15].

The analysis of the Russian adolescents' self-descriptions shows the predominance of personal identification over social one, the weak integration of the Self-image with the We-image, the predominance of religious identity, and the weakness of time perspective. The revealed significant differences $(p<0.05)$ in the frequency of identifying reflexive identity features, as well as the positioning of a person's status by the adolescents, are consistent with the results of many other identity studies. The Russian adolescents most often mentioned their ethnicity in combination with their physical characteristics. In general, the clustering of the Russian self-description features showed a structurally more differentiated picture compared to that of the Mongols. Perhaps this is due to the variety of socialization factors in modern Russian society.

According to the research, most adolescents are characterized by adequate self-esteem. Inadequate self-esteem depends on gender: the boys have high self-esteem twice often than the girls, who have low one. This is consistent with the foreign studies data: in early adolescence, in parallel with the active self-awareness development, girls' self-esteem usually falls [16]. Difficulties in emotional and evaluative characteristics self-assessment of the Mongolian adolescents are determined by cross-cultural factors: the significance of traditional communication norms and generic values (saving 
emotions, ethnocultural values of restraint / modesty, traditional norms of evaluative dependence on society) [11].

The adolescents' self-descriptions do not contain clear features (in accordance with the empirical data of other authors) related to communication with peers, including ones of the opposite sex, and to appearance. So, for example, when describing a person, adolescents experiencing violent bodily changes during puberty indicate the skin condition much more often than subjects of other ages [5]. Rather, the body ego features are at an unconscious level, since ideas about one's own body and its boundaries are formed before an individual fully masters his native language. Besides, such results may be associated with the cross-cultural taboo of this topic.

Our research hypothesis about the existence of culturally determined differences in personal and social identities components of Mongolian and Russian adolescents was additionally confirmed during the empirical testing based on the hierarchical cluster analysis. The analysis of the grounds for dividing the clusters of the Mongolian adolescents' selfdescription features allows us to single out three parameters: perception of oneself as an activity or reflective subject; separation of personal and social identity; separation of membership in small and large groups. The last division parameter is also confirmed by the research data of Russian sociologists. The data obtained in the survey and interviewing made it possible to single out two dichotomous factors: involvement in the group (alienation) and concreteness, i.e. membership in a particular small group (abstractness) [17]. The analyzed grounds for dividing the clusters of the Russian adolescents' self-description features allow us to discuss three parameters: perception of oneself as an activity or reflective subject; predominance of personal identity over social one and religious self-identification.

Considering the relationship problem between social and personal identities, we support those authors (more about this: [18]) who consider social identity as primary in relation to personal one. The use of the clustering procedure in the study [19-20] showed the inclusion of personal characteristics in a person's social identification. Our data, obtained earlier on preschoolers, confirm the primary influence of social representations (and social identity) on personal identity formation [21-22].

Summarizing the cluster analysis results of both samples, we can state about partial autonomy of personal identity from social one. At the same time, the personal self features, which do not directly depend on an individual (his age, the general assessment of his personality, which depends more on social stereotypes, belonging to the human race) are included in the context of the social self. In the Mongolian sample, such a personal identity feature as a name is closely "intertwined" into social identity in the minds of Mongolian adolescents. Thus, the subjective internal criterion for dividing self-description features into personal and social identity ones is the degree of involvement and control of a subject in these features formation. This assumption, based on the empirical data, is theoretically confirmed in the work of A. Sh. Tkhostov and E.I. Rasskazova [3]. In the concept of bodily identity, the authors consider a subject's control feeling as a universal identity criterion ("a universal phenomenological experience") [3]

\section{Conclusions}

The identity feature of Mongolian adolescents is their greater involvement in various groups, compared with Russian ones. Firstly, this is expressed by their more frequent statement of membership in large and small groups. This determines the social, normative and emotional content of Mongolian adolescents' membership, conditioned by the traditional culture values. The significance of traditional ideas about male and female roles is manifested through the differentiated gender characteristics among Mongolian adolescents. Secondly, we have identified the social orientation of Mongolian adolescents (a perspective vision of oneself as a "good citizen" and "a worthy family member" which is not found among Russian adolescents).

The identity feature of Mongolian adolescents is the polarization of their social and personal identity, in comparison with Russian ones. At the same time, in the cluster analysis results of both samples, the personal self features, which do not directly depend on an individual, are included in the social self. This allows us not only to evaluate this fact as supercultural, but also forces us to reconsider personal identity components.

\section{Acknowledges}

This work is supported by the Russian Foundation for Basic Research (project № 16-23-03005 «Auto- and heterostereotypes of indigenous minorities of Mongolia: culture, language, self-identification»). The authors are grateful to their colleagues from Khovd State University for the organizational and linguistic support provided during the empirical research.

\section{Ethical issue}

Authors are aware of, and comply with, best practice in publication ethics specifically with regard to authorship (avoidance of guest authorship), dual submission, manipulation of figures, competing interests and compliance with policies on research ethics. Authors adhere to publication requirements that submitted work is original and has not been published elsewhere in any language.

\section{Competing interests}

The authors declare that there is no conflict of interest that would prejudice the impartiality of this scientific work.

\section{Authors' contribution}

All authors of this study have a complete contribution for data collection, data analyses and manuscript writing.

\section{References}

[1] Oyserman D, Elmore K, Smith G. Self, Self-Concept, and Identity. Handbook of Self and Identity. London: The Guilford Press. 2012.

[2] Erikson E. Childhood and Society. Saint-Petersburg: Lenato, AST, fond University book, Publ. 1996.

[3] Tkhostov ASh, Rasskazova EI. Identity as a psychological construct: possibilities and limitations of the interdisciplinary approach. Psychological research. 2012;5(26):55-64.

[4] Terner Dzh. The social impact. Saint-Petersburg: Piter Publ. 2003.

[5] Sobol' TV. The problem of social identity formation in the context of global social changes. Philosophy and cosmology. 2012;1(10):211-230

[6] Dugarova TTs. The phenomena of ethnic self-awareness linguistic realities in the phenomenology concept of personality development and being (based on the Buryat mentality studies). Personality development. 2018;2:183-208.

[7] Dugarova TTs, Badiev IV, Filippovich YN, Dugarov TZC. The mentality changes of modern Buryats (based on the psychosemantic research results). New research of Tuva. 2-17;3: 112-124.

[8] Rumyantseva TV. Psychological counseling: diagnostics of relationships in a couple. Saint-Petersburg: Speech Publ. 2006.

[9] Novikova IA, Zhambal O. The relation of personality traits and cross-cultural adaptation of Mongolian students. Moscow: RUDN Publ. 2015.

[10] Sumiya O. The study of individual psychological characteristics of Mongolian high school students. Psychology and Pedagogy: methods and problems of practical application. 2015;45:8-12. 
[11]Dugarova TTs, Badiev IV. Cultural and value orientations of Russian (Russian and Buryat) and Mongolian students. Bulletin of the peoples' friendship University of Russia. Series: Psychology and Pedagogy. 2017;14(2):190-200.

[12] Tsendzhavyn E. Psychological analysis of teenagers' interests in educational and extracurricular activities: $\mathrm{PhD}$ Thesis. Moscow. 1990

[13] Aronson E, Uilson T, Eikert R. Social Psychology. Psychological laws of a human behavior in society. Saint-Petersburg: primeEVROZNAK Publ. 2002.

[14] Sherman DK, Uskul AK, Updegraff JA. The role of the self in responses to health communications: A cultural perspective. Self and Identity. 2011;10(3):284-294.

[15] Maiers D. Social Psychology. Saint-Petersburg: Piter Publ. 2011.

[16] Timoshina IN. Intensification of gender identity in adolescence (review of the foreign studies). Modern foreign psychology. 2014;3(3):41-51.

[17]Danilova EN, Yadov VA. The contours of social sectional identification in modern society. Social identification. Moscow: In-t sotsiologii RAN Publ. 1993.

[18] Rasskazova EI, Tkhostov AS, Emelin VA. Identity as self-relation: individual variations of the value of completion, development and social acceptance of identity. Bulletin of the South Ural State University. Series «Psychology». 2014;7(4):13-18.

[19] Khairullina ER, Bogdanova VI, Slepneva EV, Nizamutdinova GF, Fatkhullina LR, Kovalenko YA, Skutelnik OA. Global climate change: Cyclical nature of natural and permanent nature of manmade processes. EurAsian Journal of BioSciences, 2019;13(2):2311-2316.

[20] Miklyaeva AV, Rumyantseva PV. Social identity of a person: content, structure, mechanisms of formation. Saint-Petersburg: RGPU named after A.I. Gertsena Publ. 2008.

[21]Cherdymova EI, Afanasjeva SA, Parkhomenko AG, Ponyavina MB, Yulova ES, Nesmeianova IA, Skutelnik OA. Student ecological consciousness as determining component of ecologicaloriented activity. EurAsian Journal of BioSciences, 2018;12(2):167-174.

[22] Trofimova EM. Perception of preschool children about a subject of influence (a peer, an adult): PhD Thesis. Moscow. 1977. 